\title{
Sustainable Biomass Value Chains Based on Poplar Plantations in European Rural Areas
}

\author{
Matthias Meyer $^{1,2}$ (D) $\cdot$ Filipa Tavares Wahren ${ }^{3}$ (D) Norbert Weber $^{1}$ (D) $\cdot$ Ronald S. Zalesny $^{4}$ (D) Martin Weih $^{5}$ (D)
}

Accepted: 30 March 2021 / Published online: 16 April 2021

(C) The Author(s) 2021

The present special issue highlights the chances and addresses the main challenges for short rotation coppices (SRC) with poplars (Populus spp.) as agricultural crops for the sustainable bio-economy. The current public perception of planting more trees on Earth as a climate mitigation action is accompanied by controversial discussions about sustainability and biodiversity of tree plantations. In contrast to many industrial plantations in the tropics, agricultural tree cropping with siteadapted tree species in the temperate zones of the world follows an agroforestry concept towards more sustainability. Disturbed land that needs remediation and underutilised agricultural land resources in rural areas can significantly benefit from SRC operations. Operated as low energy-input biomass production ecosystems, these crops can significantly improve the habitat value for flora and fauna due to their perennial character, acceptance of ground vegetation below trees, erosion control, and strong reduction of spraying and fertilising.

Many processes and risks that occur along with land use change after the establishment of poplar SRC crops have been investigated throughout the last decades. An earlier special issue of BioEnergy Research ["Environmental Impacts of Short Rotation Coppice (SRC) Grown for Biomass on Agricultural Land", Sept. 2012, vol. 5(3)] covered the topic

Matthias Meyer

matthias.meyer@tu-dresden.de

1 Chair of Forest Policy and Forest Resource Economics, Institute of Forest Economics and Forest Management Planning, TU Dresden, Pienner Str. 8, D-01737 Tharandt, Germany

2 Molecular Tree Physiology Group, Institute of Forest Botany and Forest Zoology, TU Dresden, Pienner Str. 7, D-01737 Tharandt, Germany

3 Institute of Soil Sciences and Site Ecology, TU Dresden, Pienner Str. 19, D-01737 Tharandt, Germany

4 Northern Research Station, USDA Forest Service, 5985 Highway K, Rhinelander, WI 54501, USA

5 Department of Crop Production Ecology, Swedish University of Agricultural Sciences (SLU), Box 7043, 75007 Uppsala, Sweden areas of SRC effects on issues of water and soil, biodiversity, and the overall impact that these plantations may have on the environment and sustainability. In contrast, the current special issue is devoted to the: (1) challenges of generating adapted plant material in order to sustainably produce poplar biomass in northern regions and (2) implementation of bio-based value chains on the basis of poplar SRC for the sustainable bioeconomy. The project consortium Dendromass4Europe (D4EU-Securing Sustainable Dendromass Production with Poplar Plantations in European Rural Areas) has demonstrated how the gap between the sustainable development of agricultural landscapes and implementing value chains for economic sustainability can be bridged, through the collaboration of three industrial partners, an NGO for nature conservation, and science partners.

The pivotal challenge for the implementation of SRC is the competition for cultivated land, a question which will likely persist in the future. Land access is affected by complex legal, ecological, and societal conditions. The contribution by Ranacher et al. has investigated the incentives and barriers that affect local farmers' willingness to invest into SRC cropping in the project D4EU's target region for SRC operations.

Another challenge is the selection of adapted operational poplar clones and the achievement of economically viable growth results on mainly marginal land. The contribution by Heilig et al. describes SRC growth monitoring and compares the suitability of operational clones with regard to water deficits in D4EU's target region, whilst Meyer et al. investigated the susceptibility of selected, legally approved poplar clones to dry post-planting conditions. Established SRC crops have access through their interconnected root system to topsoil water and groundwater. SRC can promote water retention in the landscape and groundwater recharge by enhancing infiltration. This way SRCs can increase flood protection, reduce nutrient export to surface waterbodies, and reduce soil erosion. The contribution by Virano Riquelme et al. describes differences between two selected SRC sites and 
neighbouring agricultural sites on sandy soils of marginal agricultural land with regard to topsoil hydrological conditions.

An additional challenge is not specific to SRC but generally important for all crops, namely the ongoing climate change, which alters climatic site characteristics. The project "Climate-Adapted Poplar Through More Efficient Breeding and Better Tools for Matching Genotype and Site" (CLAP) aims at developing the poplar bio-economy market in parts of Northern Europe. Most of the existing poplar clone material is not well adapted to both the current and predicted growing conditions in northern areas with otherwise favourable growth conditions. Karacic et al. studied growth and quality traits of poplar breeding material in a Swedish clone trial. Two other contributions, Adler et al. and Vico et al., foster the exploitation of the genus' Populus variability in phenology in order to provide more clones for sustainable biomass value chains at higher latitudes.

A particular challenge is the case-specific, very complex, and broad variability of conditions for establishing a sustainable value chain that covers the full path from the SRC acreage up to the completion of production and market replication. As an example, the radius of inbound transportation activities for the delivery of SRC logs must be reliably short in order to avoid high transportation distances. Spinelli et al. have developed and tested harvesting technologies that allow the highest possible efficiency under consideration of the actual availability of machine equipment in the project region of D4EU. Another aspect of sustainable SRC operations is the restriction of harvesting activities to the winter months in order to avoid impact on the flora and fauna during the vegetation period. As a consequence of winter harvest, log storage must be organised to allow permanent feedstock supply until the next harvesting period. Günther et al. have tested different poplar SRC log storage methods and compared their effect on mechanical and chemical properties of wood or bark.

On the demand side of SRC-based value chains, innovative raw material utilisation and market replication of the new biobased materials are required. In D4EU, four new bio-based materials will be produced. Eco-fungicidal moulded fibre parts containing poplar bark for bio-based packaging represent the application of one of these materials. The fungicidal effect of poplar bark, which can be utilised as an additive in bio-based packaging, was assessed by Bremer et al.

The sustainability of the SRC-based, interconnected value chain complex was subject to monitoring. Methods were adapted in order to find hot spots that are most relevant for the assessment of the socio-economic sustainability (Fürtner et al.). In addition, the methodology for a suitable Life Cycle Assessment (LCA), encompassing a broader spectrum of impact categories, was identified (Perdomo et al.).

The guest editors for the present special issue were as follows: Dr. Matthias Meyer, professor Norbert Weber, and Dr. Filipa Tavares Wahren, all TU Dresden, Department of Forest Sciences in Tharandt, Germany; professor Martin Weih, Swedish University of Agricultural Sciences, Uppsala, Sweden; and Dr. Ronald S. Zalesny, Jr., USDA Forest Service, Rhinelander, WI.

Funding Open Access funding enabled and organized by Projekt DEAL. The project Dendromass4Europe, D4EU, has received funding from the Bio-Based Industries Joint Undertaking under the European Union's Horizon 2020 Research and Innovation Programme under the grant agreement No. 745874. The project Climate Adapted Poplar, CLAP, has received funding from the Swedish Research Council FORMAS (grant 942-2016-20001).

Open Access This article is licensed under a Creative Commons Attribution 4.0 International License, which permits use, sharing, adaptation, distribution and reproduction in any medium or format, as long as you give appropriate credit to the original author(s) and the source, provide a link to the Creative Commons licence, and indicate if changes were made. The images or other third party material in this article are included in the article's Creative Commons licence, unless indicated otherwise in a credit line to the material. If material is not included in the article's Creative Commons licence and your intended use is not permitted by statutory regulation or exceeds the permitted use, you will need to obtain permission directly from the copyright holder. To view a copy of this licence, visit http://creativecommons.org/licenses/by/4.0/.

Publisher's Note Springer Nature remains neutral with regard to jurisdictional claims in published maps and institutional affiliations. 